\title{
OSTEONECROSIS OF THE JAW (MRONJ)
}

HOSPITAL SÍRIO-LIBANÊS

Oral Medicine
B.M. Benites ${ }^{1}$, W.Miranda-Silva ${ }^{1}$, FP. Fonseca ${ }^{2}$, ER. Fregnani ${ }^{1}$

1. Oral Medicine Department, Hospital Sírio-Libanês, São Paulo, Brazil.

2. Department of Oral Surgery and Pathology, School of Dentistry, Universidade Federal de Minas Gerais, Belo Horizonte, Brazil. 3. Unit of Marrow Transplant, Hospital Sírio-Libanês, São Paulo Brazil

INTRODUCTION
Bisphosphonates have been widely used for the treatment of
onco-hematological diseases that presents high rates of bone
metastases and osteoporosis. Although this therapeutic modality
has contributed to the improvement in quality of life and survival
of patients, MRONJ is an important cause of morbidity. The
diagnosis and strategies of support and prevention of MRONJs
are of competence of the dental team. Although MRONJ was
described 15 years ago, little knowledge is observed about its
possible side effect in the oral cavity.

\section{OBJECTIVE}

The objective of the present study was to evaluate the knowledge of dentists on MRONJ, identifying the drugs and the possible adverse effects in the oral cavity.

\section{METHODS}

A questionnaire was applied for 500 dentists, divided into three sections:

\section{1) Professional profile}

2) Knowledge on antiresorptive (AR), as bisphosphonates, or other antiangiogenic drugs (AA)

3) Familiarity with approaches prevention

\section{RESULTS}

Among the 500 dentists interviewed, 175 (35\%) were general practitioners and 325 (65\%) were specialists, of which 65 have more than one specialty. It is important to point out that only 10 dentists had expertise in Oral Surgery, Oral Pathology or Oral Medicine. Sixty-six percent of the total have more than 5 years graduated.

\section{CONCLUSION}

Knowledge about MRONJ and its dental preventive measures by dentists are not sufficient. Thus, it is clear the need to improve the training of dentists, as well as the establishment of measures of continuing education, so that the dentists will know how to recognize patient at risk for MRONJ.

\section{REFERENCES}

Ruggiero SL, Mehrotra B, Rosenberg TJ, Engroff SL. Osteonecrosis of the jaws associated with the use of bisphosphonates: a review of 63 cases. J Oral Maxillofac Surg. 2004; 62(5):527-34.

Marx RE. Pamidronate (Aredia) and zoledronate (Zometa) induced avascular necrosis of the jaws: a growing epidemic. J Oral Maxillofac Surg. 2003; 61(9):1115-7.

Ruggiero SL, Dodson TB, Fantasia J, Goodday R, Aghaloo T, Mehrotra B, et al. American Association of Oral and Maxillofacial Surgeons position paper on medication-related osteonecrosis of the jaw--2014 update. J Oral Maxillofac Surg. 2014; 72(10):1938-56.

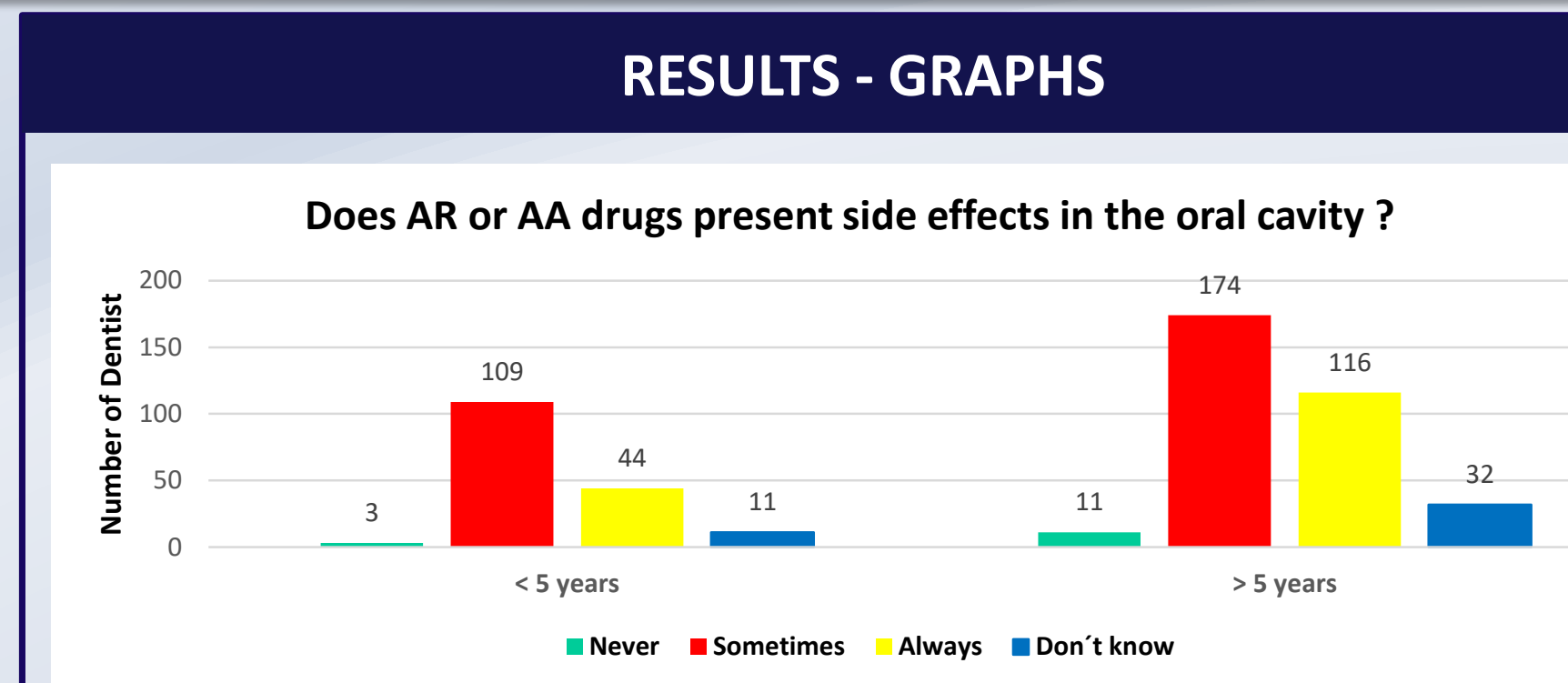

Which side effect of these drugs is the most prevalent in the oral cavity?
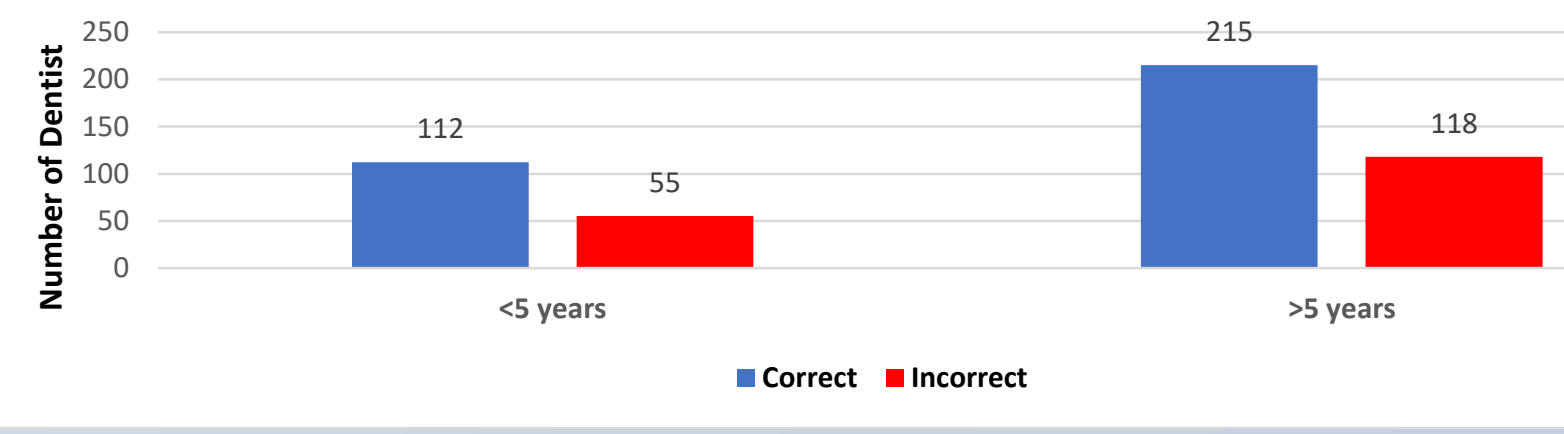

The use of these medications may be indicated for the treatment of which pathologies?

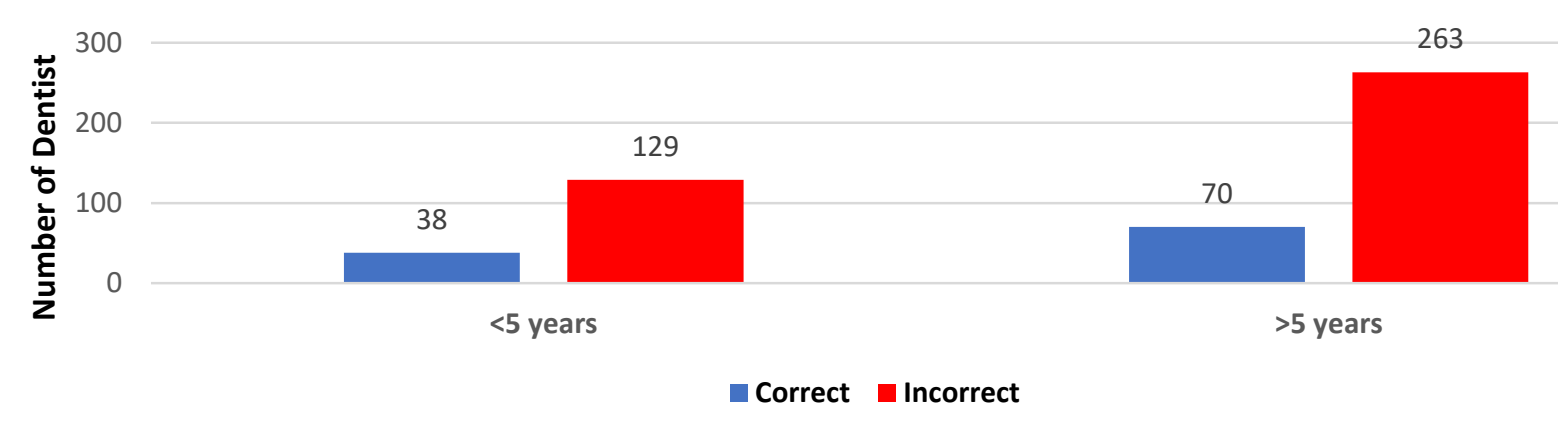

After how many doses does intravenous bisphosphonate use become a risk for BRONJ?

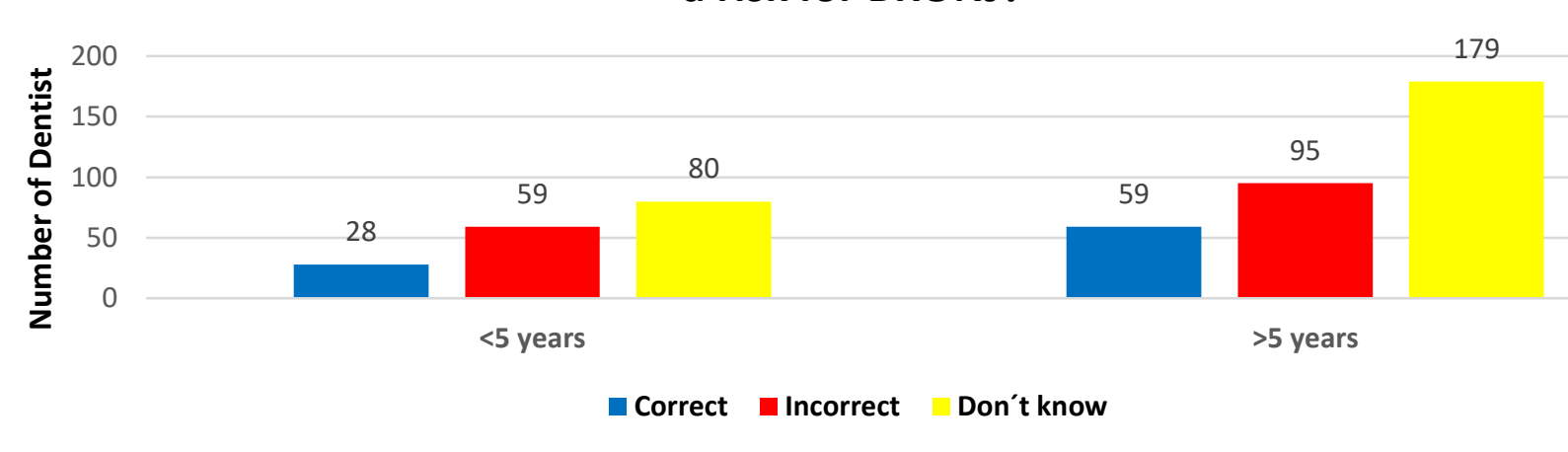

Have you ever diagnosed a case of MRONJ?

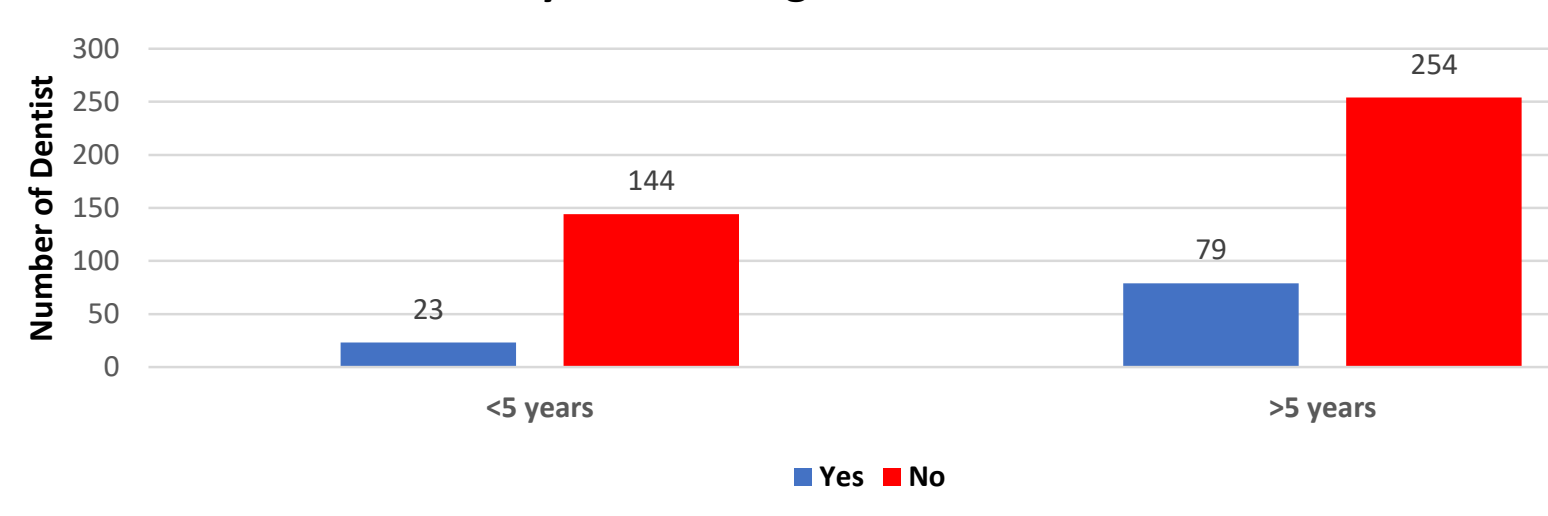

At what stage of MRONJ should you refer patients for follow-up and evaluation with the specialist?

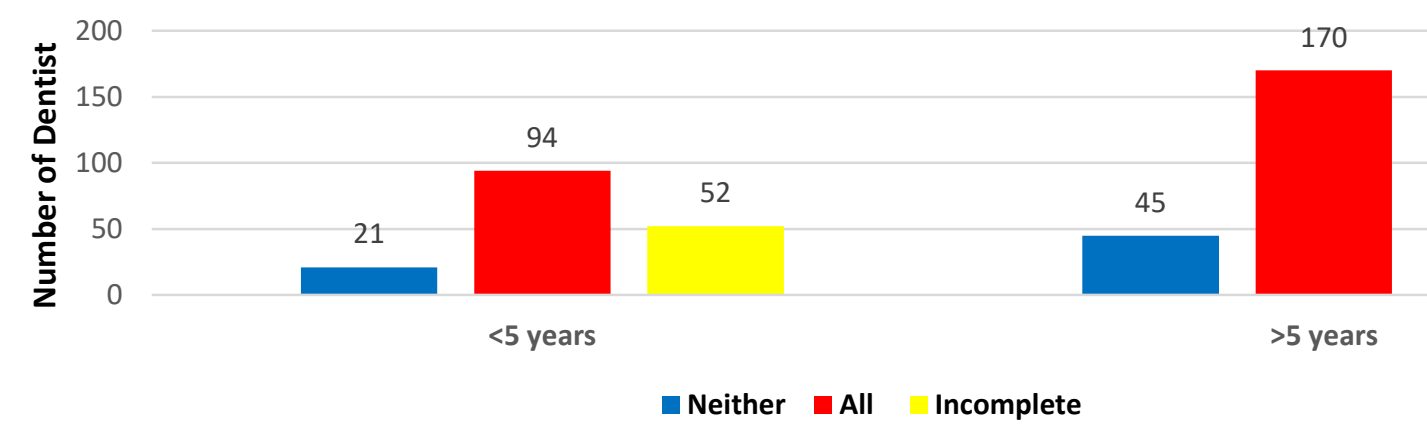

Which preventive measures are important in the prevention of MRONJ?
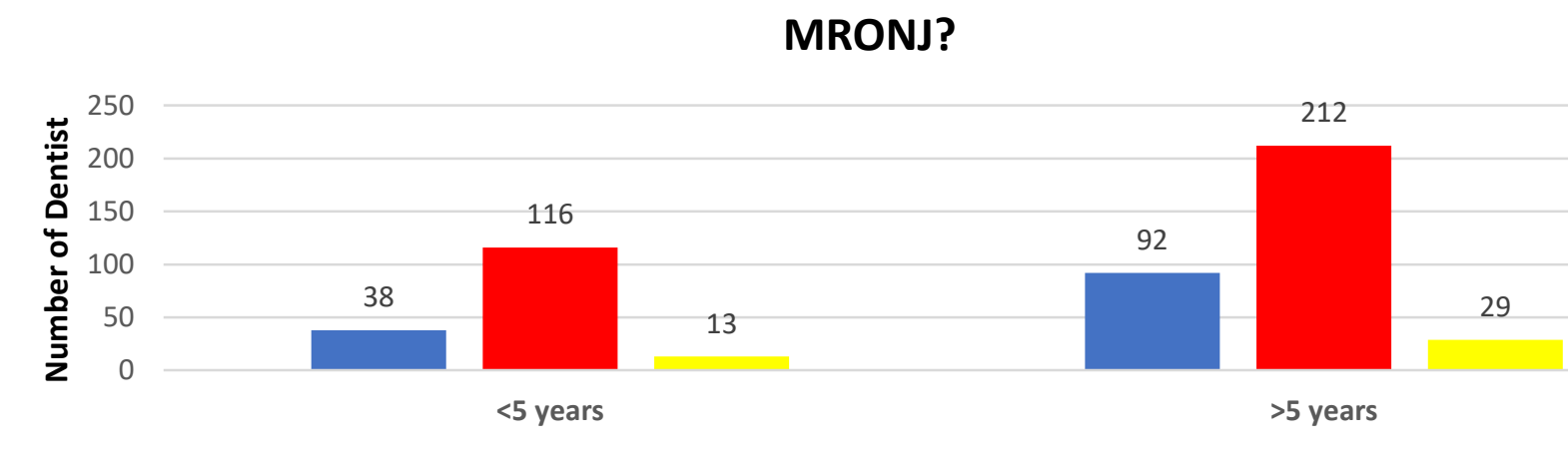